\title{
MJN OPERATING ROOM HAND HYGIENE PRACTICES: ARE PATIENTS REALLY SAFE? AN OBSERVATIONAL STUDY
}

\author{
Manfred Mortell*, Jana Botha, Lim Swee Yieng \\ King Fahd Hospital, Riyadh, Saudi Arabia \\ *Corresponding Author's Email: mannymortell@gmail.com
}

\begin{abstract}
Background: Health care providers (HCP) who work in the operating room (OR) or post anesthesia care unit (PACU) have a greater opportunity to cross contaminate patients because of high workloads and frequent patient contact events. The current prevalence of health care-associated infections (HCAI) is a major health concern and patient contact in the OR and PACU can be a contributing factor due to microbial contamination. Methods: An observational study was conducted on the hand hygiene $(\mathrm{HH})$ compliance of HCP working in the OR and PACU of a tertiary health-care facility in Saudi Arabia. The participants in the study comprised of surgeons, anesthetists, and circulating and PACU nurses. The observations and data collection were performed by two OR and PACU clinical resource nurses, who had been trained by the infection control and prevention department. Results: The study included 2300 opportunities for $\mathrm{HH}$ compliance and observed 200 nurses, 100 surgeons and 100 anesthetists. HH compliance in the OR and PACU was highest among nurses; $>90 \%$ and lowest among physicians, surgeons $<70 \%$; followed by anesthetists $<50 \%$. Conclusion: Adherence to HH guidelines by OR and PACU nurses was acceptably higher than anesthetists and surgeons.
\end{abstract}

Keywords: Operating Room, Hand Hygiene, Patients Safety

\section{INTRODUCTION}

Biblically, HH was first mentioned in Exodus 30:18 - 21. "So they shall wash their hands and feet, so they die not." In Islam, the Qur'an (5.6) affirms that washing and cleanliness "Wudhu" (ablution) is paramount without exception (Mortell et al., 2013). Scientific application of infection control practices commenced more than 180 years ago, in the historic study by Dr. Ignaz Semmelweis (Hebra, 1847; Hebra, 1848; Routh, 1849). $\mathrm{HH}$ is endorsed internationally as the single most important factor in preventing HCAI (Momen \& Fergie, 2010; Takahashi \& Turale, 2010; Ott \& French, 2009; Akyol, 2007; NHS, 2007; Pratt, 2007; CDC, 2002), which is any infection that a person develops as a result of treatment in hospital. However, despite more than one century of $\mathrm{HH}$ knowledge and evidence based recommendations; the magnitude of HCAI and the importance of adherence to $\mathrm{HH}$ practices amongst HCP, continues to be low (Takahashi \& Turale, 2010;
Askarian \& Khallooee, 2006; Trampuz \& Widmer, 2004; Pittet et al., 2004). Non-compliance with $\mathrm{HH}$ recommendations is widely acknowledged as the most imperative amendable cause of HCAI with compliance ranging from 20-50\% (Maxfield \& Dull, 2011; Mani et al., 2010; Ott \& French, 2009; Aragon et al., 2005).

It has been estimated that HCAI are responsible for 90,000 deaths per year in the United States of America (USA) (Maxfield \& Dull, 2011; Smith \& Lokhorst, 2009), Canada 8,000 deaths annually (Momen \& Fergie, 2010) and 5,000 deaths per annum in the United Kingdom (UK) (Smith, 2009). HCAI are the most frequently reported adverse event in health care delivery (Kaier et al., 2012). This is a global dilemma with more than 1.4 million people are acquiring infections in hospitals per year (Devnani et al., 2011; Momen \& Fernie, 2010; Pittet \& Donaldson, 2005), and HCAI costs in the USA escalating to approximately 4.7 - 6.5 billion dollars per year (Stone et al., 2005; 
Trampuz \& Widmer, 2004) and costing the UK National Health Service (NHS) 1 billion pounds per annum (Davis, 2010).

\section{RESEARCH METHODOLOGY}

\section{Design}

This study employs an observational descriptive approach which was deemed most appropriate to collect data about $\mathrm{HH}$ compliance amongst OR and PACU HCP. The design was selected because observation is an excellent method for the assessment of behavior in conjunction with skills and clinical performance (Polit \& Hungler 1999). However, this method of structured observation requires the observer to be knowledgeable in the area under investigation (Polit \& Hungler 1999). Both of the observers were clinical resource nurses (CRNs) from the actual practice area of the OR. They were additionally trained by the infection control and prevention department (ICPD) to collect HH data accurately.

\section{Setting and Sample}

The population of the study composed of Surgeons (100), Anesthetists (100), and nurses (200), who were working in the OR and the PACU of a tertiary healthcare facility in Saudi Arabia. Data were collected over a period of 6 months, by means of non-participant structured observation. The CRNs observed the OR and PACU HCPs through the practice day, employing the WHO 5 moments of hand hygiene to determine HCP compliance (Figure 1 and 2). In order not to create a behavioral change in those HCPs being observed, the observed HCPs were not informed about who was being observed, why or by whom. Data was collected periodically, by observation, between the hours of 0800 and 1600, with a definitive compilation of 2300 opportunities for $\mathrm{HH}$ compliance.

\section{RESULTS}

The results of the study concluded that compliance to WHO HH guidelines by OR and PACU nurses was superior to that of anesthetists and surgeons.

\section{A Culture of Safety}

Improving quality and safety in health-care is a central issue world-wide and two historic reports from the US Institute of Medicine (IOM) in 1999 and 2001 that highlighted deficiencies in the quality of care and patient safety. Mounting confirmation discloses the importance of assessing and improving safety culture in efforts to eradicate HCAI (Speroff et al., 2010; Pronovost et al., 2006) and as a consequence a discipline of 'safety science' has evolved with the specific application to health-care delivery (IIan \& Fowler, 2005). The goal of the culture of safety is to reduce the risk of harm to patients. However, despite a global transparent culture of safety and advances in health-care systems, the provision of health-care continues to be associated with a potential range of threats to patient safety (Devnani et al., 2011; Mani et al., 2010; Cronenwett et al., 2007). Primum non nocere 'above all, do no harm' is considered a fundamental of health care practice, however, the IOM (2000) landmark report of To Err is Human, revealed that hospitalized patients are not safe. The disturbing escalation in morbidity and mortality among patients amplifies dilemmas about HCP competence (Gaba, 2004) and one of the most notorious health-care dilemmas is the continued escalation of HCAI (Momen \& Fernie, 2010) which has placed HCP under increased inquiry to provide safe care (Needleman \& Buerhaus, 2003).

Safety is defined as freedom from psychological and physical injury (Joint Commission International, 2011; Shojania et al., 2001; Institute for Healthcare Improvement, 2014) and a safe environment reduces the risk for illness and injury, improves or maintains the patients' functional status, and increases the patients' sense of well-being. The Joint Commission International (JCI) is a USA based organization that accredits health care organizations and programs. The JCI declared mission is to continuously improve health care for the public, in collaboration with other stakeholders, by evaluating health care organizations and inspiring them to excel in providing safe and effective care of the highest quality. A JCI strategy to improve patient safety and provide effective care was the implementation of the patient safety goals (Table 1). Unfortunately, compliance with $\mathrm{HH}$ recommendations remains unacceptably low.

Table 1: Joint Commission: Hospital National Patient Safety Goals - 2011

\section{JCI PATIENT SAFETY GOALS}

Identify patients correctly Improve staff communication

Reducing harm to patients who take high alert medications

- Reduce the risk of Health Care Associated Infections Preventing multi-drug-resistant organism infections

Preventing central line associated blood stream infections

- Identify Patient Safety Risks 
Susceptible patient groups who often require assistance in achieving a safe environment include infants, children, 'sick' young adults and geriatrics. All these patient groups could possibly require surgery, either planned or unplanned as emergencies. The care environment in which HCP provide treatment to patients can determine the quality and safety of patient care (Gaba, 2004). HCP must utilize and apply evidence-based knowledge, skills, and experience to care for the various and changing needs of the patient. The WHO highlighted the need for new strategies to improve $\mathrm{HH}$ practices based on low compliance and defined the ' 5 moments' of $\mathrm{HH}$ to advance patient safety (Erasmus et al., 2010; WHO, 2009).

\section{The operating room and post anesthesia care unit}

The OR and PACU is a latent patient risk environment for the acquisition of a HCAI, as OR and PACU HCP frequently touch patients. Failure to implement $\mathrm{HH}$ strategies may result in contamination of equipment, implants and the patient themselves maybe reservoir for pathogens that could cross-infect another patient (Pittet et al., 2003). There is no doubt, that patient contact in the OR and PACU by HCP can contribute to HCAI, however, the data in the literature is limited related to adherence of $\mathrm{HH}$ guidelines in these sequestered specialty areas (Krediet et al., 2011). Implementing $\mathrm{HH}$ strategies such as the ' 5 moments' of $\mathrm{HH}$ in the OR and PACU has been identified in the literature as challenging due to a dearth of defining criteria, work related dynamics, patient turnover and a need for the comprehension of the application rationale (Bellaard - Smith et al., 2012). HCP fail to perform $\mathrm{HH}$ in the PACU mostly during the time of admission (only $19.6 \%$ ) and $12.5 \%$ among already admitted patients who failed to continued care, with compliance ranging from $13-20 \%$ (Pittet et al., 2003).

An additional concern is that $\mathrm{HH}$ compliance rates for medical staff are consistently lower than those for nurses. However, Collins \& Hampton (2005) and Nazarko (2009) claimed that physicians have excellent HH skills compared to nurses. Yet, Figure 1 from this observational study supports the view consistent with the current $\mathrm{HH}$ data in the literature that physician compliance remains low.

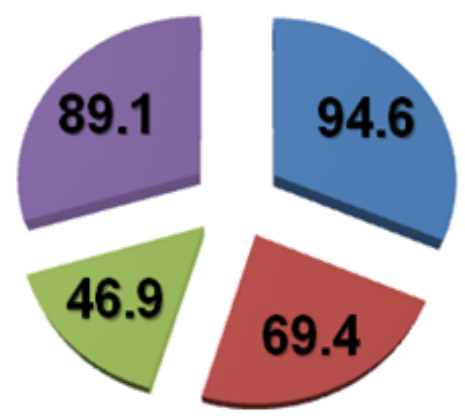

OR nurse

Surgeon

Anesthetist

PACU nurse

\section{Figure 1: Operating room - WHO '5 moments' Hand Hygiene compliance (2009)}

\section{The Surgeon}

The concept of effective $\mathrm{HH}$ is familiar to all $\mathrm{HCP}$, particularly surgeons, who are meticulous about 'scrubbing' before performing an operation. However, effective $\mathrm{HH}$ should extend beyond an individual OR and into other OR areas such as PACU, offices, staff lounges, the patients' clinical environment and extended hospital areas, such cafeterias. Krediet et al. (2011) concurred that HH was rarely performed by members of the surgical team at the time entry or exit from the OR. Surgeons were observed repeatedly, touching the patients, equipment and implements without performing subsequent $\mathrm{HH}$. The study also confirmed that surgeons who were $\mathrm{HH}$ non-compliant also exited the OR with hands that were visibly soiled on completion of a procedure or operation, (Figure 2).

The study investigates the reason of noncompliance of many highly educated and trained HCP. Most of the surgeons performed $\mathrm{HH}$ rarely, and maintained low $\mathrm{HH}$ compliance rates which placed their patients at risk. A compliance of $>70 \%$ by physicians it appears, can be attained by on-going nurse initiated education, observation and feedback, (Mortell, 2012). However, without the constant support and encouragement from nursing team members, surgeons revert effortlessly to a non-compliance $\mathrm{HH}$ compliance score of $<60 \%$ (Mortell, 2012). It is a frightening indictment that doctors do not comply with evidence based $\mathrm{HH}$ recommendations and must be repeatedly reminded and encouraged to perform 
something as simple as HH. Moreover all surgeons and all physicians must remember the Hippocratic Oath that states 'first do no harm'.

\section{The Anesthetist}

Anesthesia is a high risk environment which is prone to potential patient infections due to the numerous invasive procedures required and performed daily in the OR. However, the data on $\mathrm{HH}$ in anesthesia is also limited, with minimal research on $\mathrm{HH}$ opportunities, activities or compliance according to the WHO recommendations (Biddle \& Shah, 2012; Loftus et al., 2011; Krediet, 2011; Koff et al., 2009). The insular character of anesthesia care is such that a HCP functions without much observation from other members of the operating team as they are obscured by the draped patient. This is in contrast to the surgeon and nurses who are in constant view of each other, scrutinized under a penetrating culture of asepsis. Nevertheless, the available literature purports that anesthetists have been found to contribute to pre and intra operative bacterial transmission due to demanding workloads and multiple time limited patient encounters. As a result working with contaminated hands is predictable (Petty, 2013; Petty, 2009). Loftus et al., (2011) identified that prior to patient contact; hands of anesthetists were discovered to be tainted by Methicillin Resistant Staphylococcus Aurous (MRSA), Vancomycin resistant enterococcusand Methicillin- Sensitive Staphy lococcus Aurous. It was observed that only $17 \%$ were performing $\mathrm{HH}$ all the time. However, Krediet et al., (2011) observed close to $100 \%$ noncompliance of $\mathrm{HH}$ activity by anesthetists prior to patient contact and documented $2 \%$ compliance with $\mathrm{HH}$ on entering the $\mathrm{OR}$ and $8 \%$ when exiting. Anesthetists were also observed to wear non sterile gloves for aseptic procedures or for excessive lengths of time when not required. However, when required to wear gloves, less than $25 \%$ did so (Krediet et al., 2011). In addition, Pittet et al., (2003) recognized that $\mathrm{HH}$ adherence in the PACU with physicians was only $9 \%$, confirming a lower compliance rate in anesthetists compared with physicians from other disciplines (Pittet et al., 2004). Thus, illustrating that adherence to $\mathrm{HH}$ guidelines globally by anesthetists is unacceptably low, which was also confirmed by the observations in this study (Figure 1 and 2).

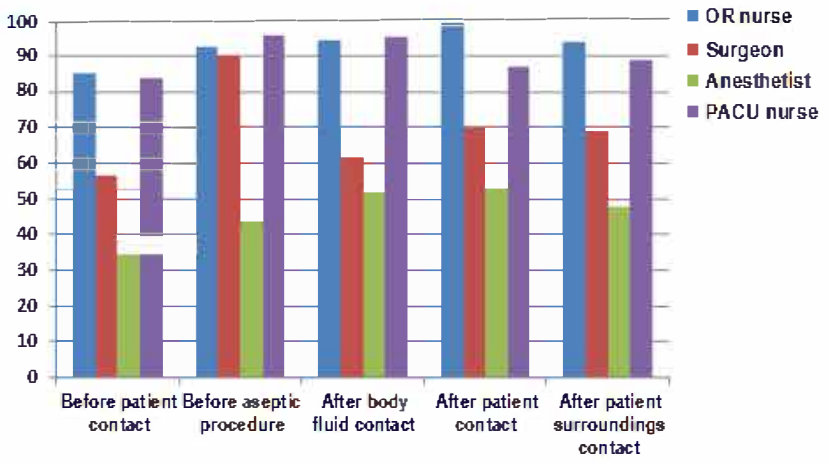

Figure 2: Operating room - WHO '5 moments' Hand Hygiene compliance (2009)

\section{The Nurse}

Nursing is a "caring profession" and emphasizes a duty of care, cause no harm? If a nurse's hands transmit pathogens to a patient, harm can and is being done. Nurses' hands come into contact with patients and are frequently contaminated during routine patient care, such as patient identification, physical assessment, recording vital signs or while touching contaminated surfaces or materials such as trolleys (Kampf, Loffler \& Gastmeier, 2009); Ogunsola \& Adesiji, 2008). Since nurses perform their duties 24 hours/ day; 7 days/ week in a health-care setting such as the OR and PACU; it is essential that nurses adhere to $\mathrm{HH}$ recommendations and policies. Furthermore, nurses are obligated by global registration councils such as the UK, Nursing and Midwifery Council (NMC), to ensure patient safety, as patient advocates. Nurses' attitudes to $\mathrm{HH}$ however have been associated with non-compliance and a lack of ownership; 'not my problem' (Maxfield \& Dull, 2011; Morrow et al., 2011; Cambell, 2010) and Pittet et al., (2003) documented that PACU nurses' HH adherence was only $20 \%$. In addition, nurses assumed that gloves were alternative to $\mathrm{HH}$, often providing care to multiple patients and failing to remove gloves for proper implementation of HH (Ott \& French, 2009). The WHO (2009) recommends the usage of gloves, first to protect the HCP from body fluids and to reduce the risk of germ dissemination not as an alternative to $\mathrm{HH}$. Nonetheless, there is currently an extensive misuse of glove usage which extends beyond the recommended indications (Eveillard, Joly-Guillou \& Brunel, 2012; Fuller, Savage \& Besser, 2011; WHO, 2009). However, these outcomes were not endorsed by 
the $\mathrm{HH}$ compliance provided by the $\mathrm{OR}$ and PACU nurses' working in this study, as compliance was consistently $>90 \%$ (Figure 2 ).

\section{The Patient}

It is important to acknowledge that patients must be considered as part of the integral practice associated with $\mathrm{HH}$ compliance. Collins and Hampton (2005) reported that patient involvement actually increases HCP HH compliance by $50 \%$. However, Duncan \& Dealey (2007) added that some patients may be reluctant to ask $\mathrm{HCP}$ about $\mathrm{HH}$, as it indicates a betrayal of trust and may label them as 'troublemakers'. Penzias (2010) added that when patients observe HCP performing 'proper' $\mathrm{HH}$, they are reassured which is an essential element to comfort patients prior to any operation. This is an imperative consideration in the perioperative period as the public are well informed that MRSA is a common cause of a surgical site infection (Kaye et al., 2009) and that 20\% of HCP are persistent carriers and 30\% are intermittent carriers (Van Belkum et al., 2009). Biofilms are ubiquitous throughout hospitals; within our bodies and because of constant shedding of organisms from biofilms, OR and PACU HCP are constantly inoculating anything they come in contact with; this includes patients (Edmiston et al., 2005; Sheretz, Bassetti \& Bassetti-Wyss, 2001). Therefore, $\mathrm{HH}$ is vital link to disrupt the cascade of infection and HCAI.

\section{DISCUSSION}

Despite remarkable scientific, medical and health care advancement over the last century HCAI still exists, resulting in substantial mortality and morbidity (Mortell, 2012). Hands are the principal route by which HCAI in the OR and PACU occur and an effective hand wash (not a surgical scrub) takes between 30-60 seconds and an effective hand rub between 20-30 seconds (WHO, 2009). The CDC (2002) even recommends a vigorous hand rub or hand wash for 15 seconds as effective. Yet research confirms that compliance to $\mathrm{HH}$ recommendations rarely exceeds $20-50 \%$. It is essential that all HCP in the OR and PACU are aware they are responsible for their own practice and can be held accountable for acts of omission which endanger the safety of their patients (NMC, 2002). Omission includes failure to comply with $\mathrm{HH}$ organizational guidelines.
Countless factors underlie meager $\mathrm{HH}$ compliance among $\mathrm{HCP}$, these include lack of awareness, skepticism due to lack of supporting scientific data (Mani, Shubangi \& Saini, 2010; Akyol, 2007). Lack of proper infection control training programmers (Karabay et al., 2005). Although $90 \%$ of NHS trusts provide infection control data during induction training, many trusts fail to provide annual updates (Nazarko, 2009).

Misconceptions regarding $\mathrm{HH}$ also contribute to low compliance, examples include, gloves as an alternative to $\mathrm{HH}$ (Morrow, 2011) along with notion that skin irritation occurs due to frequent $\mathrm{HH}$ practices (Mani, Shubangi, \& Saini, 2010; Karabay et al., 2005). In addition these we must also take into account increased workloads, under-staffing, limited time, lack of role models, lack of organizational commitment to effective $\mathrm{HH}$ practices, disagreement with policies and protocols, lack of HCP motivation (Kampf, Loffler \& Gastmeier, 2010; Mani et al., 2010). Lack of HH facilities such as running water, sinks, antiseptic or non-antiseptic soaps, alcohol rubs and proper hand towels also play a role in low compliance with $\mathrm{HH}$ practice (Mani et al., 2010; Kampf, Loffler \& Gastmeier, 2009).

The list is boundless, with strategies to improve $\mathrm{HH}$ compliance including, staff training and follow up, leadership to ensure that $\mathrm{HH}$ products are available and easily accessible (Kampf \& Loffler 2010). Campbell (2010) even recommends that non-compliant staff should be disciplined to avoid violation of hospital policy.

This HH dilemma is a patient safety and advocacy concern which is categorized as a failure to implement known knowledge and expected practices related to $\mathrm{HH}$, essentially validating a "theory-practice-ethics gap" (Mortell, 2012). The evidence, derived from the literature suggested that indifference to evidence based practice recommendations. $\mathrm{HCP}$ at most levels have been provided with the $\mathrm{HH}$ education, are aware of organizational $\mathrm{HH}$ recommendations, yet choose to be blatantly noncompliant. One possible explanation for $\mathrm{HH}$ noncompliance maybe, there is an "ethical gap" between failures to "do no harm" (Mortell et al., 2013). 


\section{CONCLUSION}

History has demonstrated that $\mathrm{HH}$ compliance will undoubtedly continue to be problematic and that $\mathrm{HH}$ compliance will remain low, regardless of the evidence based practice recommendations or endorsements for more education and research. Scientific and educational arguments are not sufficient and in light of this. Thus the authors' recommendations purport that that leadership in health care organizations (HCO); first, emphasize the moral and ethical obligations of $\mathrm{HH}$ to the $\mathrm{HCP}$, especially to physicians, surgeons and anesthetists on commencement of employment, during employment and enduring as a contractual obligation. Second, that HCO leadership must provide on-going feedback to all HCP which informs and validates their compliance or noncompliance. Third, strategies must be employed, emphasizing a message of safety and a duty of care when caring for the patients. In addition, infection control departmental HH surveillance must include segregated specialty care areas such as the OR and PACU in order to accomplish $100 \% \mathrm{HH}$ compliance.
$\mathrm{HH}$ is a responsibility shared by all stakeholders, which include administrators, leaders, all HCP and patients. Addressing compliance is the duty of all HCP. However, senior HCP such as consultants, directors of clinical nursing, nurse managers and senior allied health professionals; must represent role models and actively indorse $\mathrm{HH}$. Seniors say and do, juniors see and do; it is as simple as $\mathrm{ABC}$.

\section{Ethical considerations}

For this type of study, formal consent was not required, as it did not identify the organization or individuals involved. The data collected was also distributed to the ICPD for their ongoing analysis to improve $\mathrm{HH}$ compliance amongst $\mathrm{HCP}$.

\section{Declaration of interests}

The author declared no potential conflicts of interest with respect to authorship, and/or publication of this article.

\section{REFERENCES}

Aragon, D., Sole, M. L. \& Brown, S. (2005). Outcomes of an infection prevention project focusing on hand hygiene and isolation practices. American Association of Critical-Care Nurses, 16(2), pp 121-132.

Askarian, M., Khalooee, A. \& Emroodi, N. N. (2006). Personal hygiene and safety of government hospital staff in Shira, Islamic Republic of Iran. Eastern Mediterranean Health Journal, 12(6), pp 768-774.

Aykol, A.D. (2007). Hand hygiene among nurses in Turkey: opinions and practices. Journal of Clinical Nursing, 16(3), pp 431-437.

Bellaard-Smith, E.R. \& Gillespie, E.E. (2012). Implementing Hand Hygiene strategies in the operating suite. Healthcare Infection, 17(1), pp 33-37.

Biddle, C. \& Shah, J. (2012). Quantification of anesthesia providers' hand hygiene in a busy metropolitan operating room: What would Semmelweis think? American Journal of Infection Control, 40(8), pp 756-759.

Campbell, R. (2010). Hand washing compliance goes from $33 \%$ to $95 \%$ steering team of key player's drives process. Healthcare Benchmarks and Quality Improvement, 17(1), pp 5-6.

Centers for Diseases Control and prevention (2002). Guidelines for hand hygiene in health care settings. Retrieved from: http://cdc.gov/handhygiene/.

Collins, F. \& Hampton, S. (2005). Hand washing and MRSA', British Journal of Nursing, 14(13), pp703 -707.

Cronenwett, L., Sherwood, G., Barnsteiner, J., Disch, J., Johnson, J., Mitchell, P., Sullivan, D. D. \& Warren, J. (2007). Quality and safety education for nurses. Nursing Outlook, 55(3), pp 122-31.

Davis, C. R. (2010). Infection free surgery: how to improve hand hygiene compliance and eradicate MRSA from surgical wards. Annals of the Royal College of Surgeons of England, 92(4), pp. 316-319. 
Devnani, M., Kumar, R., Sharma, R. K. \& Gupka, A. K. (2011). A survey of hand washing facilities in the outpatient department of a tertiary care teaching hospital in India. Journal of Infection in Developing Countries, 5(2), pp 114-118.

Duncan, C. P. \& Dealey, C. (2007). Patient's feelings about hand washing, MRSA status and patient information. British Journal of Nursing, 16(1), pp 34-38.

Edmiston, C. E., Seabrook, G. R., Cambria, R. A., Brown, K. R., Lewis, B. D., Sommers, J. R., Krepel, C. J., Wilson, P. J., Sinski, S. \& Towne, J. B. (2005). Molecular epidemiology of microbial contamination in the operating room: Is there a risk of infection? Surgery, 138(4), pp 573-582.

Erasmus, V., Daha, T. J., Brug, J., Richardus, J. H., Behrendt, M. D. Vos, M. C. \& van Beeck, E. F. (2010). Systematic Review of Studies on Compliance with Hand Hygiene Guidelines in Hospital. Infection Control and Hospital Epidemiology, 31 (3), pp 283-294.

Eveillard, M., Joly-Guillou, M. L. \& Brunel, P. (2012). Correlation between glove use practices and compliance with hand hygiene in a multicenter study with elderly patients. American Journal of Infection Control, 40(4), pp 387-388.

Fuller, C., Savage, J. \& Besser, S. (2011). The Dirty Hand in the Latex Glove: A Study of Hand Hygiene Compliance when Gloves are Worn. Infection Control and Hospital Epidemiology, 32(12), pp 1194-1119.

Gaba, D. M. (2004). The Future Vision of Simulation in Health Care. Quality and Safety in Health Care, 13(Supp 1), pp 2-10.

Hebra, F. (1847). Hochst wichtige erfahrungen uber die aetiologie der an gebaranstalten epidemischen puerperalfieber. Zeitschrift der kk Gesellschaft der ärzte zu wien, 4(1), pp 242 - 244.

Hebra, F. (1848). Fortsetzung der erfahrungen uber die aetiologie der an gebaranstalten epidemischen puerperalfieber. Zeitschrift der kk. Gesellschaft der arzte zu wien, 5.

IIan, R. \& Fowler, R. (2005). Brief History of Patient Safety Culture and Science. Journal of Critical Care, 20(1), pp 2-5.

Institute of Medicine (IOM) (2000). To Err Is Human: Building a Safer Health System. Washington DC: National Academy Press.

Joint Commission International (JCI) International patient safety goals update (2011). Retrieved from: http://www.jointcommission.org/

Kaier, K., Wilson, C., Hulscher, M., Wollersheim, H., Huis, A. \& Borg, M. (2012). Implementing bundles of infection prevention and management. Infection, 40(2), pp 225-228.

Kampf, G., Loffler, H. \& Gastmeier, P. (2009). Hand hygiene for the prevention of nosocomial infections. Deutsches Ärzteblatt International, 106 (40), pp 649 - 55.

Kampf, G. \& Loffler, H. (2010). Hand disinfection in hospitals-benefits and risks. Journal of the German Society of Dermatology, 8(12), pp 978-983.

Karabay, O., Sencan, I., Sahin, I., Alpteker, H., Ozcan, A. \& Oksuz, S. (2005). Compliance and efficacy of hand rubbing during in hospital practice: Medical principles and Practice. International Journal of the Kuwait University, 14(5), pp 313-317.

Kaye, K. S., Anderson, D. J., Sloane, R., Chen, L., Choi, Y., Link, K., Sexton, D. J. \& Schmader, K. E. (2009). The effect of surgical site infection on older operative patients. Journal of the Geriatric Society, 57(1), pp 46-54. 
Koff, M. D., Loftus, R. W., Burchman, C. C., Schwartzman, J. D., Read, M. E., Henary, E. S. \& Beach, M. L. (2009). Reduction of intraoperative bacterial contamination of peripheral IV tubing through the use of a novel device. Anesthesiology, 110 (5), pp 978-985.

Krediet, A. C., Kalkman, C. J. \& Bonten, M. J. Gigengack, A. C. \& Barach, P. (2011). Hand hygiene practices in the operating room: an observational study. British Journal of Anesthesia, 107(4), pp 553-558.

Loftus, R. W., Muffly, M. K., Brown, J. R., Beach, M. L., Koff, M. D., Corwin, H. L., Surgenor, S. D., Kirland, K. B. \& Yeager, M. P. (2011). Hand contamination of anesthesia providers is an important risk factor for intraoperative bacterial transmission. Anesthesia and Analgesia, 112(1), pp 98-105.

Mani, A., Shubangi, A. M. \& Saini, R. (2010). Hand hygiene among health care workers. Indian Journal of Dental Research, 21(1), pp 115-118.

Maxfield, D. \& Dull, D. (2011). Influencing hand hygiene at spectrum health. Physician Executive, 37(3), pp 30-32.

Momen, K. \& Fergie, G. R. (2010). Nursing activity recognition using inexpensive game controller: an application to infection control. Journal of European Society for Engineering and Medicine, 18(6), pp 393 -408.

Morrow, E., Griffiths, P., Gopal, R. G. \& Flaxman, D. (2011). Somebody else's problem? Staff perceptions of the sources of control of MRSA. American Journal of Infection Control, 39(4), pp 284-291.

Mortell, M. (2009). A Resuscitation Dilemma -Theory Practice Ethics. Is there a theory practice ethics gap? Journal of the Saudi Heart Association, 2(1), pp 149-152.

Mortell, M. (2012). Hand Hygiene compliance: is there a theory practice ethics gap? British Journal of Nursing, 21(17), pp 1011-10114.

Mortell, M., Balkhy, H., Tannous, E. \& Jong, M. T. (2013). Physician 'defiance’ toward hand hygiene compliance: Is there a theory practice ethics gap? Journal of the Saudi Heart Association, 2(1), pp 149-52.

Nazarko, L. (2009). Potential pitfalls in adherence to hand washing in the community. British Journal of Community Nursing, 14(2), pp 64-68.

Needleman, J. \& Buerhaus, P. (2003). Nurse staffing and patient safety: current knowledge and implications for action. International Journal of Quality in Health Care, 15(4), pp 275-277.

NHS (2007). National Hand Hygiene NHS Campaign, Compliance with Hand Hygiene - Audit Report. Retrieved from: http://www.documents.hps.scot.nhs.uk/hai/infection-control/national-hand-hygiene-campaign/auditreport-2007-12-27.pdf

Nursing and Midwifery Council (NMC) (2008). The code: Standards of conduct, performance and ethics for nurses and midwives. Retrieved from: http://www.nmc-uk.org/General-public/what-people-should-expectfrom-a-nurse-or-midwife/The-standards-we-expect-nurses-and-midwives-to-follow/The-code

Ogunsola, F. T. \& Adensiji, Y. O. (2008). Comparison of 4 methods of hand washing in situations of inadequate water supply. West African Journal of Medicine, 27(1), pp 24-28.

Ott, M. \& French, R. (2009). Hand hygiene compliance among health care staff and students in a mental health setting. Mental Health Nursing, 30(11), pp 702-704.

Penzais, A. (2010). Don't get complacent with hand hygiene. Emergency Department of Nursing, 13(5), pp 54-55.

Petty, W. C. (2009). PACU - Why hand washing is vital. Journal of Perianesthsia Nursing, 24(2), pp 250-253.

Petty, W. C. (2013). Closing the Hand Hygiene Gap in the Post Anesthesia Care Unit: A Body Worn Alcohol Based Dispenser. Journal of Perianesthsia Nursing, 28 (2), pp 87-97.

Pittet, D. \& Donaldson, L. (2005). Clean care is safer care: a worldwide priority. The Lancet, 366(9493), pp 1246- 
1247.

Pittet, D., Simon, A., Hugonnet, S., Pessoa- Silva, C. L., Sauvan, V. \& Perneger, T. V. (2004). Hand hygiene among physicians: performance beliefs and perceptions. Annals of Internal Medicine, 141(1), pp 1- 8.

Pittet, D., Stephen, F., Hugonnet, S., Akakpo, C., Souweine, B. \& Clergue, F. (2003). Hand cleansing during post anesthesia care. Anesthesiology, 99(3), pp 530-535.

Polit, D. \& Hungler, B. (1999). Nursing Research: Principles and Methods, Lippincott, New York.

Pratt, R. J., Pellowe, C. M., Wilson, J. A., Loveday, H. P., Harper, P. J., Jones, S. R., McDougall, C. \& Wilcox, M. H. (2007). Epic 2: National Evidence Based Guidelines for Preventing Health Associated Infections in NHS Hospitals in England. Journal of Hospital Infection, 65(1), pp S1-S64.

Pronovost, P. J., Sexton, J. B., Pham, J. C., Goeshel, C. A.,Winters, B. D. \& Miller, M. R. (2006). Measurement of quality and assurance of safety in the critically ill. Clinic and Chest Medine, 30(1), pp 169-79.

Routh, C. H. F. (1849). On the Causes of the Endemic Puerperal Fever of Vienna. Medico-Chirurgical Transactions, 32, pp 27-40.

Sheretz, R.J., Bassetti, S. \& Bassetti-Wyss, B. (2001)."Cloud" health-care workers. Emerging Infectious Diseases, $7(2), \mathrm{pp} 241-244$.

Shojania, K. G., Duncan, B. W., McDonald, K. M. Wachter, R. M. \& Markowitz, A. J. (2001). Making health care safer: a critical analysis of patient safety practices. Evidence Report/Technology Assessment, 43, pp 1- 668.

Smith, J. M. \& Lokhurst, D. B. (2009). Infection control: can nurses improve hand hygiene practice? Journal of Undergraduate Nursing Scholarship, 11(1), pp 1-6.

Smith, S. M. (2009). A review of hand washing techniques in primary care and community setting. Journal of Clinical Nursing,18(6), pp 786-790.

Speroff, T., Nwosu, S., Greevy, R., Weinger, M. B., Talbot, T. R. \& Wall, R. J. (2010). Organizational culture: varaiation across hospitals and connection to patient safety climate. Quality and Safety in Health Care, 19(6), pp 592-596.

Stone, P. W., Braccia, D., Larson, E. (2005). Systematic review of economic analyses of health care-associated infections. American Journal of Infection Control, 33(6), pp 501-509.

Takahashi, I. \& Turule, S. (2010). Evaluation of individual and facility factors that promote hand washing in aged care facilities in Japan. Nursing and Health Sciences, 12(1), pp 127-134.

The Institute for Health care Improvement (2014). Retrieved from: http://www.ihi.org/ihi.

The Joint Commission (2008). Patient safety goals. Retrieved from: http://www.jointcommission.org/patient safety.

Trampuz, A. \& Widmer, A. F. (2004). Hand Hygiene: a frequently missed lifesaving opportunity during patient care. Mayo Clinic Proceedings, 79(1), pp 109-116.

Van Belkum, A., Melles, D. C., Nouwen, J., Van Keewen, L. W. \& Van Wamel, W. (2009). Co-evolutionary aspects of human colonization and infection by staphylococcus aurous. Infection, Genetics and Evolution, 9(1), pp 32-47.

World Heart Organization (WHO) (2009). Guidelines on Hand Hygiene in health care. First global patient safety challenge. Clean care is safer care. Geneva, Switzerland. Retrieved from: www.who.int.gpsc/5may/tools/ 9789241597906/en 